Portland State University

PDXScholar

2014

Drainage Reversals Due to Tectonic Uplift: an Investigation through Modeling

Max Gregory Bordal

Portland State University

Follow this and additional works at: https://pdxscholar.library.pdx.edu/honorstheses

Let us know how access to this document benefits you.

Recommended Citation

Bordal, Max Gregory, "Drainage Reversals Due to Tectonic Uplift: an Investigation through Modeling" (2014). University Honors Theses. Paper 95.

https://doi.org/10.15760/honors.97

This Thesis is brought to you for free and open access. It has been accepted for inclusion in University Honors Theses by an authorized administrator of PDXScholar. Please contact us if we can make this document more accessible: pdxscholar@pdx.edu. 
Drainage reversals due to tectonic uplift:

an investigation through modeling

\section{by \\ Max Gregory Bordal}

An undergraduate honors thesis submitted in partial fulfillment of the

requirements for the degree of

Bachelor of Science

in

University Honors

and

Geology

Thesis Adviser

Dr. Adam Booth

Portland State University

2014

Bordal Honors Thesis 


\title{
Drainage reversals due to tectonic uplift: an investigation through modeling
}

\author{
Submitted to \\ Urban Honors College \\ Portland State University \\ By \\ Max G Bordal \\ June 8, 2014
}

\begin{abstract}
In mountainous landscapes throughout the world bedrock dominated river channels record a history of the tectonic and climatic evolution of the drainage basins that contain them. In traditional analysis of river profiles, uplift and erosion are considered to be in balance in a steady state. In this study the transient state of a drainage basin is explored and numerically modeled, where a Gaussian shaped pulse of tectonic uplift overwhelms the river's incision and forces a diversion of the drainage network. I review the derivation of and use the detachment limited stream power equation to execute a model to find the physical condition that produce these dramatic drainage response. The Eel River and the unique tectonics of the nearby Mendocino Triple Junction, a well-researched case study in this phenomenon, provide context and parameters. The results of my models suggest that a rapid increase in uplift and a low erosion factor are the two most important conditions for a diversion response.
\end{abstract}

\section{Approval}

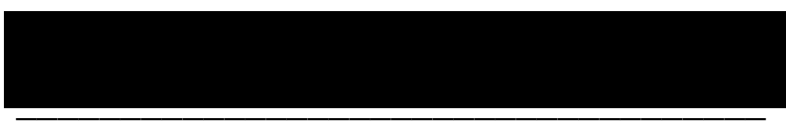

Dr. Adam Booth, Thesis Advisor

Date

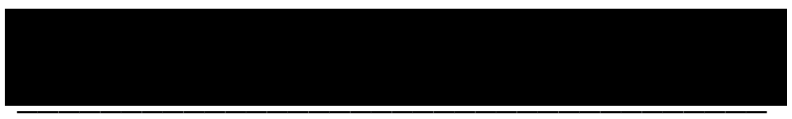

Michael L. Cummings, Department Chair

Date 


\section{Research Question}

What are the physical conditions necessary to produce reversals in stream systems?

\section{Introduction}

When an existing river is faced with tectonic uplift, it responds one of two ways. When uplift rate is slower than erosion rate the river carves its ways through and continues its original direction. If the uplift rate is greater than the river's ability to erode, it changes course (fig. 1). These responses have been recognized and qualitatively examined in drainage basins since $19^{\text {th }}$ century, however quantitative investigations and predictive models of these responses are relatively recent. A typical drainage basin has all elements for each of these subfields of geology to uniquely explore. A holistic approach is necessary to model a river's response to tectonic disturbances such as uplift. One must account for hydrology, geomorphology, underlying physical principles of the water channel, and tectonic forces. All these controlling factors must be investigated while a numerical model will make assumptions and simplifications such as constraining flow to one dimension. Understanding and modeling what drives the response of river to transient tectonic uplift is the focus of the investigation presented here. The underlying balance of erosion and uplift, at a drainage basin scale but limited to a 1-D longitudinal profile, will be modeled. The previous research on the drainage response to due tectonics in the Northern California Coast Range will provide this model with boundary conditions and context. This region has drainage networks that show sign of reversal and antecedence resulting from the unique tectonic influence of the nearby Mendocino Triple Junction (MTJ) causing a northward migrating pulse of rapid uplift. When the downstream uplift of drainage basin overcomes the river's erosional power the river the response is drainage reversal. My hypothesis is that a rapid increase in uplift and a low erosion factor lead to a reversal condition; by focusing on the underlying parameters that control these two elements in a numerical model this hypothesis is tested. 


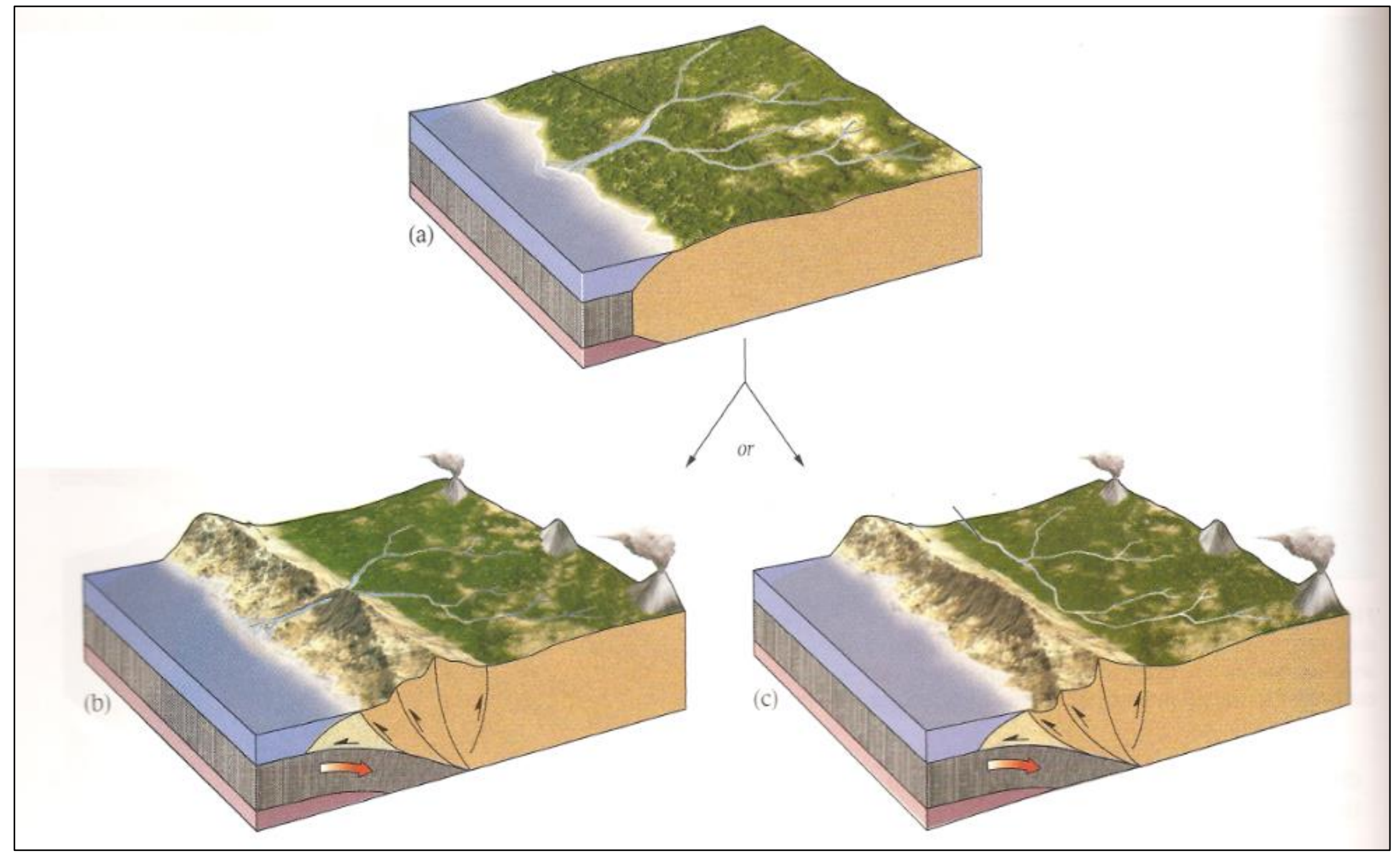

Figure 1(a) shows a stream network, near a plate margin, flowing from its headwaters to the ocean. When presented with tectonic uplift due to subduction, the streams behavior follows either case (b) where the network becomes antecedent and cuts through the mountain range, or case (c) where the stream network is diverted and follows a new path. Image modified from (Marshak, 2001). 


\section{Background}

Valleys form when flowing streams and rivers are fed from many smaller branches of streams. These branches make up a network of water draining from high elevation to low; this network makes up a drainage basin or watershed (Ritter et al., 2011). A simple dendritic pattern with tributaries joining the main river at small angles, all pointing downstream in a general " $\mathrm{v}$ " shape is the steady state case that incorporates uniform geologic properties, as shown in Figure 2.

When this is not

observed the

geomorphic history

of the system must

hold the answers

(Ollier, 1981). The

area of interest in

this investigation is

to quantitatively

study the interaction

Climate ( $Q$ water and $Q$ sediment)

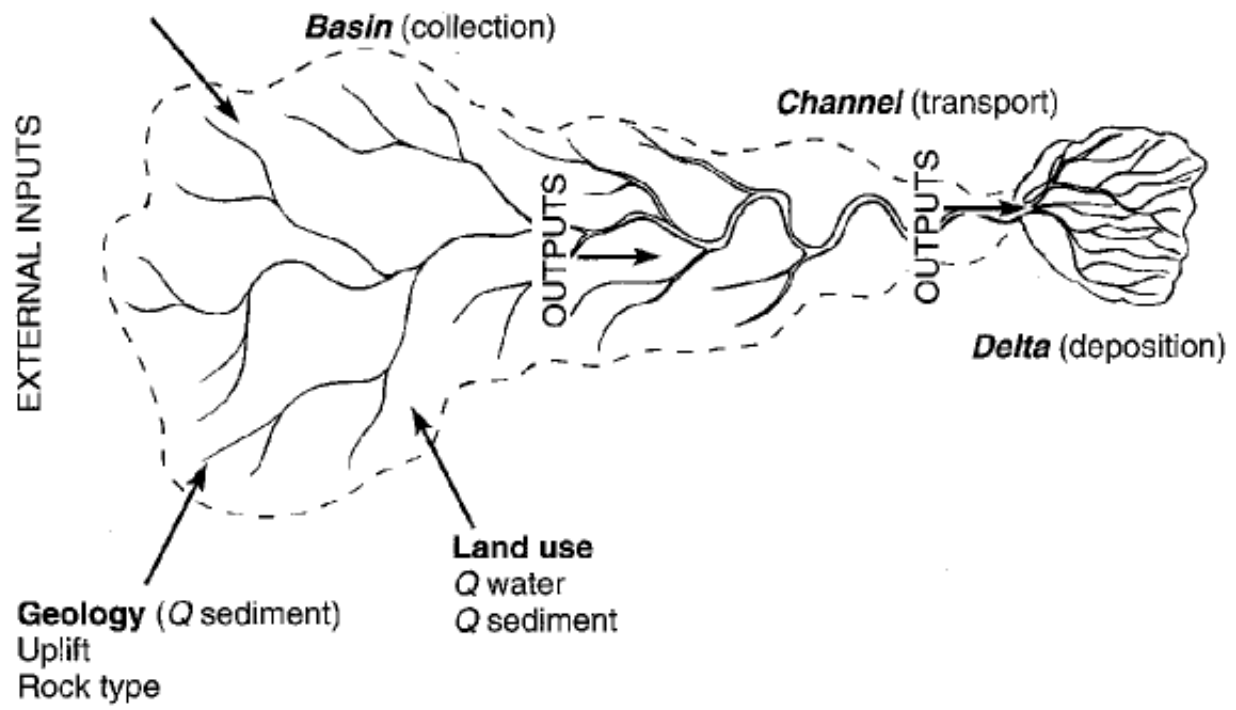

Figure 2 A diagram showing the above ground components of a drainage basin

between the river including inputs and outputs of the stream network. $Q$ is the variable for discharge.(Ritter et al., 2011)

and the land in a

drainage basin through the vehicle of a longitudinal profile numerical model. This smaller scale model incorporates simplifications such as no deposition of material and does not allow for lateral meandering. Drainage basins are defined by a topographic divide and the structure of the basin comes from the geomorphic and tectonic processes (Petts and Amoros, 1996). The main 
controlling factors are erosion and uplift; these are also the controlling factors in the simplified model which thus has drainage basin scale implications.

The basin is the unit in which water and sediment flow from the hillslopes at the head waters to the mouth downstream (Petts and Amoros, 1996). River systems do not just erode and transport sediment; they can also store and produce it as well, but given time the material will eventually leave the system. This process, called denudation, results in a net lowering of the

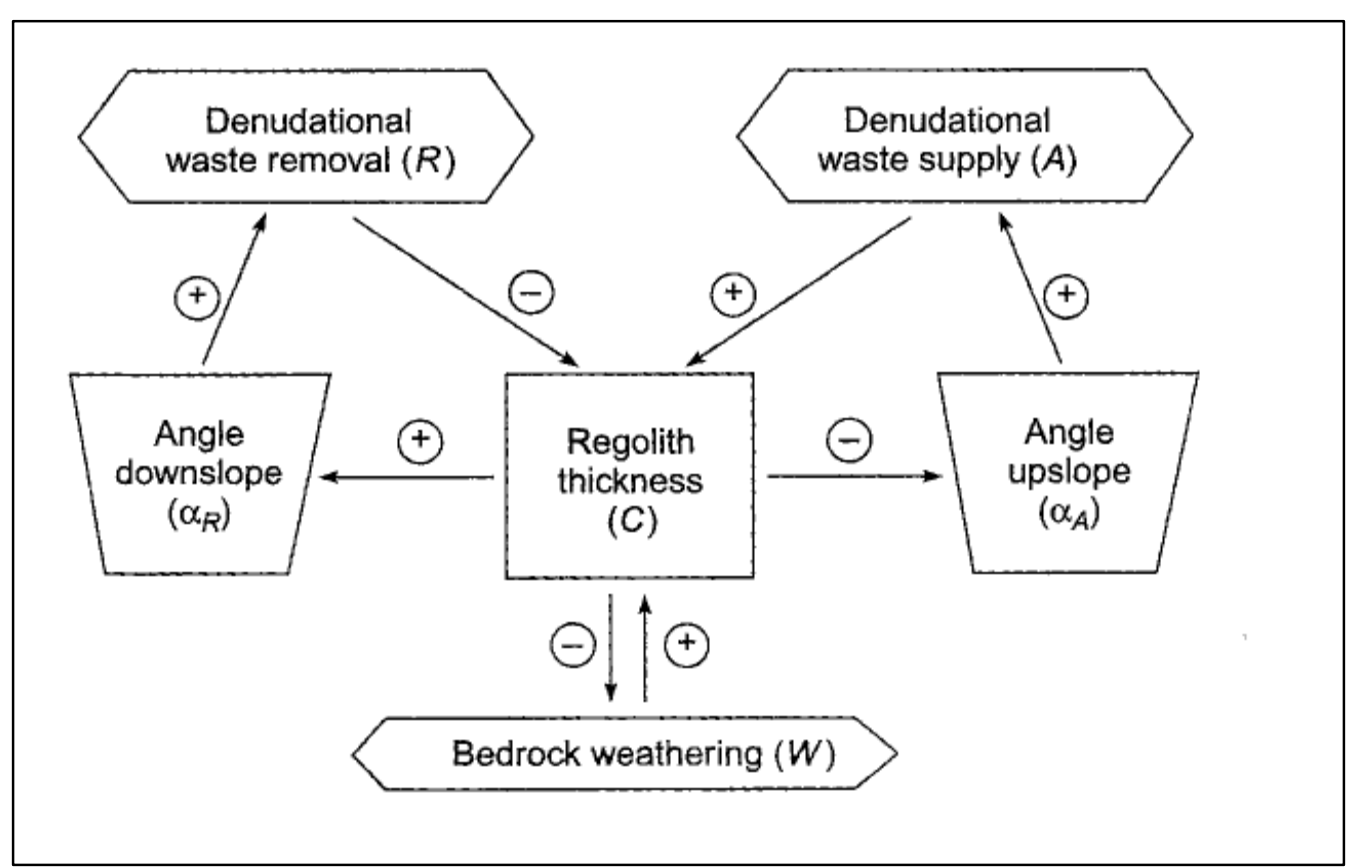

Figure 3 Diagram of the controlling factor and relationships of denudation (Ritter et al., 2011). basin surface (Ritter

et al., 2011). In

Figure 3 the elements involved with

denudation are shown. Erosion rate, the fundamental element of denudation physically changes the basin's geometry. The change

in elevation gradient modifies the denudation rate. There is a "recursive loop" nature to relationship between the river and its basin; as a river erodes and incises the surface of its basin, the changes to the basin in turn control the erosion. There are two general states a given river system will tend toward: a steady state, where erosion and uplift are balanced, and a transient state, where the drainage system responds to an unbalanced relationship between uplift and 
erosion. The signs of transience, like large scale reversals, are recorded in the landscape and provide the specific location of large changes in baselevel.

The initiation and distribution of knickpoints are small scale of example of this transient state feedback loop readily found nature and studied in fluvial networks. A rivers gradient goes under fast readjustment when a small segment of the profile is oversteepened causing focused erosion at that point (Ritter et al., 2011). A perturbation like this can push the landscape away from steady state conditions as adjustments are not contemporaneous throughout the basin (Crosby and Whipple, 2006).This aggressive channel incision can and will migrate up stream in an effort to balance this base level drop (Ritter et al., 2011). The behavior of this incision can modeled as a product of longitudinal slope and drainage area (Crosby and Whipple, 2006). In the case of knickpoints erosion propagates through the landscape; in the case of the model presented in this study, uplift propagates longitudinally upstream. Both push the landscape into a transient or disequilibrium condition and the readjustments that follow are trying to "restore order".

The erosive strength can also be quantified as the product of the velocity of water, the amount of sediment and the volume of water (Marshak, 2001).The load of sediment brought on by this erosion in tandem with the water discharge are the main controlling factors on river pattern (Ritter et al., 2011). The physical laws and mathematical formulas behind these forces are key to understanding and are essential for any modeling.

The water and sediment within the drainage system that will be focused on is that contained in the stream channels themselves. Water contained in a channel is controlled by basic forces of friction and gravity (Petts and Amoros, 1996). Discharge, whose formula is displayed in Equation 1, is the quantification of the amount of water that flows past a specific point of a channel in a given duration. The product of the channels width (w) and depth (d) or crossBordal Honors Thesis 
sectional area, $\alpha$, is multiplied by the depth-averaged velocity, $\mathrm{v}$, to give the discharge $\mathrm{Q}$ (Ritter et al., 2011).

$$
Q=w d v=\alpha v
$$

$$
\text { Units of }\left[\mathrm{L}^{3} \mathrm{~T}^{-1}, \mathrm{~L}=\text { Length, } \mathrm{T}=\text { Time }\right]
$$

The velocity of the water can be calculated by using the Manning equation, shown in Equation 2 (Petts and Amoros, 1996).

$$
v=\frac{R^{2 / 3} \times S^{1 / 2}}{n}
$$

The Manning equation finds velocity by using the product of the channels slope, $\mathrm{S}$, to the one half power and hydraulic radius, $\mathrm{R}$, to the two thirds power. This can be found by taking the ratio of the cross sectional area and the wetted perimeter. All this is divided by the Manning number, $\mathrm{n}$, which is an empirical coefficient measuring the channels roughness (Petts and Amoros, 1996). The manning number for a mountain stream with a rocky bed is about 0.047 (Ritter et al., 2011). The velocity, and in turn the discharge, is the driving factor in an open channel system. The balancing of this force is the resistance to flow based on the conditions and behavior of flow. The internal conditions of the how the water behaves can be described by the Reynolds number (Ritter et al., 2011). The Reynolds number or Re can be found by taking the product of the velocity, the hydraulic radius, $\mathrm{R}$, and the waters density, $\mathrm{p}$. This number is then divided by the molecular viscosity, note as $\mu$, the resulting number determines if the water behaves in a laminar or turbulent way (Petts and Amoros, 1996). The rivers of interest behave in turbulent way and this leads to shear stress. 
A river channels ability to incise is linked to the ability to dislodge a particle from the bed. This is determined by the shear stress or stream power equation. When a particle is set in motion by the moving water the dragging force can be expressed by shear stress (Ritter et al., 2011). Shear stress, $\tau$, is the product of the fluids density, $\rho$, gravity, $\mathrm{g}$, depth, $\mathrm{d}$, and slope, $\mathrm{S}$, shown in Equation 3. Since specific weight, gamma, is the product of density and gravity substituted in Equation 3a.

$$
\begin{aligned}
& \tau=\rho g d S \\
& \tau=\gamma d S
\end{aligned}
$$

Another way of quantifying the erosional strength of water in a channel is the stream power equation, shown below in Equation 4. Stream power, $\omega$, is force of the water which equals the product of discharge, $\mathrm{Q}$, the specific weight of water, $\gamma$, and slope of the channel, $\mathrm{S}$ (Petts and Amoros, 1996). The stream power equation is a the product of the width and velocity, from Equations 1 and 2, of a river multiplied by shear stress, Equation 3a.

$$
\omega=\gamma Q S
$$

This expression serves as a basis for the erosion portion of the model in this investigation as it factors in water discharge, which can be estimated by drainage area, and slope, two easily measurable parameters. A river channel will incise its bed will occur when there is higher stream power than that needed to detach stream bed particles.

Plate tectonics is the mechanism that builds mountains, causes earthquakes, and shapes the continents known today. The outer most rigid shell of the Earth, called the lithosphere, floats atop a more malleable section called the asthenosphere (Marshak, 2001). The lithosphere or crust 
is either: continental, thick and light, or oceanic, dense and thin. The Earth is broken up into about 20 different moving plates. Without recounting the life's work of Harry Hess and Alfred Wagner, the interaction of these plates and the resulting uplift is of interest for this investigation. Specifically, oceanic-continental subduction zones and the lateral slipping of a transform boundary, both of which can be found in Northern California. The triple junction, north of San Francisco is a point where a two transform boundaries and a convergent or trench boundary meet; a map of this is shown in Figure 4 (Marshak, 2001).

These interactions cause folds, faults and uplifts on the neighboring landscape. The uplift patterns in the coastal mountains around the MTJ are unique. In response to crustal thickening, thinning, and mantle flow a "double humped" or domal uplift with a dip in the middle is generated (Lock et. al., 2006). How a drainage network response to this increase in uplift is dependent on the rate at which the MTJ migrates. Typically plates move at between $1-15 \mathrm{~cm}$ per year (Marshak, 2001). A resulting uplift can be as fast as $8 \mathrm{~m}$ per 1000 years or $1 \mathrm{~cm}$ per year (Schumm et al., 2002). This often drastic alteration to the surface of the drainage network directly affects the controlling factors to the channel flow, such as slope, discharge and sediment supply.

The forces of plate tectonics have literally shaped the earth we know today and are continuing to do so right beneath our feet. All drainage basins in existence are affected by

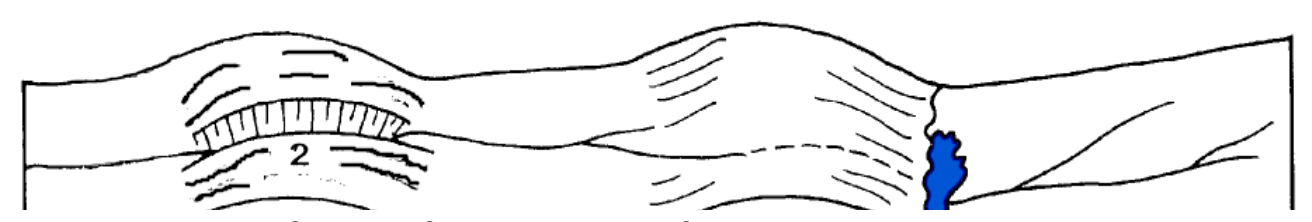

tectonic

Figure $5 \mathrm{~A}$ river, flowing from right to left, responses in two ways to tectonic warping. 1 shows the river pooling at the base of the warp and then traveling parallel. 2 show the river becoming antecedent by cutting a gorge through the warp (Ollier, 1981).

forces. Over a long enough time spans with steady 


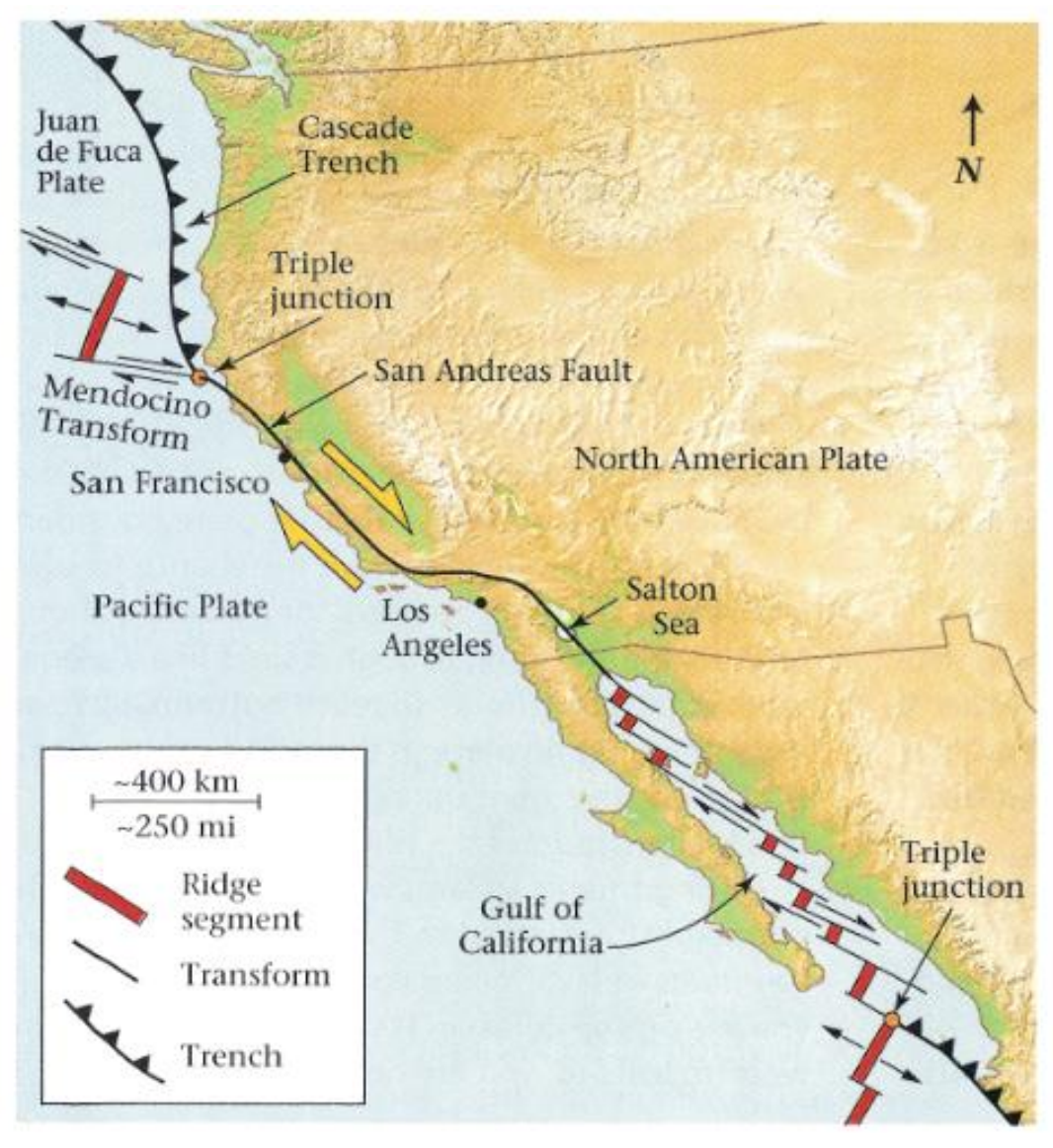

Figure 4 the west coast of the United States (oblique view) showing the triple junction(MTJ) where the Cascade trench, the Mendocino Transform and the San Andreas Fault meet (Marshak, 2001). rate of erosion and uplift

drainage basins tend to go

toward equilibrium. In cases

where the deformation rate

changes dramatically from

its previous state, the

drainage system is disrupted

(Schumm et al., 2002). On

smaller scales the fluvial

systems near active plate

margins can be altered fast

enough (on a geological

time scale) to cause

dramatic responses. A

drainage system's response

to tectonic warping is shown

in Figure 5, this is one

example of the varying reactions to the alteration (Ollier, 1981). In case 1 the downstream slope becomes negative and water ponds up before diversion. Understanding the symbiotic relationship between the basin and river has been used to predict floods and estimate sediment yield/erosion rates (Ritter et al., 2011). Studying a water system and the controlling processes through numerical and computer modeling allows for quantitative results. These quantitative results can be used to for prediction of the response behavior. 


\section{Methods}

I use a model that captures the fundamental processes of river erosion and tectonic uplift, specific combinations of which produces reversals or non-reversal outcomes. By focusing on specific responses, antecedence vs. reversal and stream piracy, the math and physics that drive a model become more manageable. The rivers of the northern California Coast Range around the Mendocino triple Junction contain both antecedent and reversal events and along with established tectonics rates to model they provide this investigation with the perfect study area. Any numerical representation of a natural system rests on stool with three legs; one leg represents the data (inputs), one the techniques (equations/calculations) and third the model (leading to results). The calibration and adjustment of each of those three elements is an ongoing process.

The previous research by Lock et al. in 2006, Willenbring et al. in 2013, and Whipple and Tucker in 1999, have provided some of the foundational elements to help create this model. Lock et al. give rates for uplift estimated by the Mendocino Crustal Conveyor geodynamic model in the study area and the specifics behind the double humped wave of uplift that caused flow reversals Eel River. Willenbring et al. links basin wide erosion rates of the Eel River and the region's history of tectonic uplift, specifically how transience affects measured cosmogenic erosion rates. Finally, Whipple and Tucker explain the physics and math behind his stream power erosion and its link to tectonics. These lines of inquiry deliver a strong foundation for my research to build on.

A modified version of stream power equation, from Whipple and Tucker, is shown in Equation 5. The term A represents drainage area, $\mathrm{S}$ is slope or stream gradient and $\mathrm{K}$ is the 
coefficient of erosion. The drainage area and slope are raised to constant exponents' $m$ and $n$ who empirically adhere to a 1:2 ratio and are assumed to be 0.5 and 1 (Whipple and Tucker, 1999).

$$
\varepsilon=K A^{m} S^{n}
$$

$\mathcal{E}$ is erosion rate. Equation 5 comes from Equation 4, here discharge is accounted for in terms of drainage area and the $\mathrm{K}$ term accounts for the fluids specific weight, climate, rock type, and channel hydraulics.

The pattern of uplift, consistent with the study area, follows a Gaussian bell curve; a pulse which will travel upstream from the mouth through the drainage basin (Willenbring et al., 2013). This shape is usually meant to describe a distribution but can be converted as a model for uplift, this is shown in Equation 6:

$$
U=U_{o} * e^{-\frac{(x-\mu)^{2}}{2 \sigma^{2}}}+U_{\text {Background }}
$$

$\mathrm{U}$ stands for effective total uplift rate, $\mathrm{Uo}$ is the maximum uplift rate, $\mathrm{x}$ is distance from the mouth to the midpoint of curve, $\mu$ is the midpoint or highest value of curve and sigma is the width or spread of the bell shape. Making a space for time substitution in which space will be substituted in to update $\mu$ and change the position of the center of the pulse. This allows the uplift field to propagate up stream through the model domain at about 30-50 mm/year (Lock et al., 2006). 
In addition the midpoint will start at enough distance away to let steady-state conditions develop with a constant uplift rate, $U_{\text {Background }}$ (see Appendix 2). Combining Equations 5 and 6 give way to a model ready partial differential equation, shown in Equation 7:

$$
\frac{\partial z}{\partial t}=U-K A^{m} S^{n}
$$

The left side of the Equation 7 also expresses elevation, as a function of change in time. In addition the variable U, described by Equation 6, will change with time as well. The main players in Equation 7 are uplift and erosion (stream-power). Equation 7 follows the form of a non-linear advection equation. When these two components are equal and balance the landscape is at steady state. When they are out of balance the behavior of the landscape if far more interesting and dramatic and can be modeled in following ways.

The analytical and numerical methods of the advection equation directly apply to the stream-power model of a one dimensional landscape profile found in Equation 7. The advection equation in its general form models the horizontal transfer of stuff, in our case regolith, measured in $\mathrm{z}$ (Pelletier, 2008). Consider that the change in elevation is the difference between elevation at the present point in time $\mathrm{p}$, and the elevation at the next point in time $\mathrm{p}+1$. In a similar fashion consider the slope term in Equation 7 as the difference between the elevation at the present spatial point along a stream $\mathrm{j}$, and the elevation at the next point along the profile $\mathrm{j}+1$ in the downstream direction.

With these considerations in mind this foundational differential equation is discretized using the forward time backward space method called an upwind scheme (Pelletier, 2008). Using 
this technique we breakdown the elevation components on both the right and left side, in terms of time and space respectively, of Equation 7 and produce Equation 8.1:

$$
\frac{Z_{j}^{p+1}-Z_{j}^{p}}{\Delta t}=U-K A^{m}\left(\frac{Z_{j+1}^{p}-Z_{j}^{p}}{\Delta x}\right)^{n}
$$

Next we multiply each side by the change in time $(\Delta t)$ this results in equation 8.2 :

$$
Z_{j}^{p+1}-Z_{j}^{p}=\Delta t\left(U-K A^{m}\left(\frac{Z_{j+1}^{p}-Z_{j}^{p}}{\Delta x}\right)^{n}\right)
$$

Adding the initial elevation $\left(Z_{j}^{p}\right)$ leads to Equation 8.3:

$$
Z_{j}^{p+1}=Z_{j}^{p}+\Delta t\left(U-K A^{m}\left(\frac{Z_{j+1}^{p}-Z_{j}^{p}}{\Delta x}\right)^{n}\right)
$$

By substituting Equation 6 for the variable $U$ back into Equation 8.3 a finished Equation 8.4 is now ready to numerically model

$$
\begin{gathered}
Z_{j}^{p+1}=Z_{j}^{p}+\Delta t\left(U_{o} * e^{-\frac{(x-\mu)^{2}}{2 \sigma^{2}}}+U_{\text {Background }}-K A^{m}\left(\frac{Z_{j+1}^{p}-Z_{j}^{p}}{\Delta x}\right)^{n}\right) \\
\Delta t=\frac{h 1}{K A^{m}}
\end{gathered}
$$

The discretization of Equation 7 into Equation 8.4 is necessary in order to be run through solving and modeling software, Matlab. Equation 8.4a finds the maximum stable time step in terms of $\mathrm{h} 1$, the horizontal grid spacing of $100 \mathrm{~m}$, and the erosion factor multiplied by the maximum of 
the drainage area. Matlab processes each variable in an equation as a vector/matrix of inputs or outputs and updating these with each iteration, over a given span of time and set initial conditions. The adjusting time step 'speeds up' or 'slows down' these iterations during computation.

In this study I ran multiple trails to calibrate and test the model, the results of which were graphically plotted. When the elevation is plotted against the horizontal distance from mouth to head waters the effects of the migrating uplift pulse on the longitudinal profile of the rivers slope is displayed. A reversal condition is considered to be when the downstream slope went below zero. Such a gradient in real life would cause the flowing water to pool if not reverse direction or divert; note diversion and reversal are used interchangeable in this study.

As this model solves for elevation in terms of both space and time I allowed the model to run for up to 10 million years, although the model stops at reversal conditions or when the pulse was more than 3000 meters beyond the stream during a non-diversion. The model stream was 1000 meters long from mouth to head waters and the uplift pulse was started 6000 meters in front of this allowing the stream to develop with the background uplift. The background uplift used in the model run is 0.9 millimeter per year. The maximum uplift rate, Uo, was set to $5 \mathrm{~mm}$ per year. A range of 20 values for sigma or width of uplift pulse were set from 10 meters to 500 meters. The pulse migrates through the river profile at 3 centimeter per year. These parameters were populated into Equation 6 as part of Equation 8.4. The exponents in the erosion power law equation, $\mathrm{m}$ and $\mathrm{n}$, are fixed to 0.5 and 1 respectively. A set of values is created for the drainage area term A, a proxy for discharge, when it is considered the function of the square of upstream distance. Additionally the erosion factor, $\mathrm{K}$, was set 20 values between $5 \mathrm{e}-6$ and $5 \mathrm{e}-4\left[\mathrm{~L} \cdot \mathrm{T}^{-1}\right]$. 
This allowed the model to be ran 400 times. Each combination of erosion factor and uplift pulse width resulting in diversion or non-diversion was recorded and plotted.

\section{Results}

A phase space consisting of all modeled combinations of $\mathrm{K}$ and $\sigma$ (fig. 6) shows where the numerical model suggests diversion, shown in red, and non-diversion, shown in blue. The top corner of the phase space (fig. 6) shows an area highlighted with a wave pattern, this zone reflects combinations of erosion and uplift width that produce physically unreasonable river profiles. An example of each condition, as marked by stars in Figure 6, diversion and nondiversion are examined in detail in Figures 7 and 8.

Figure 7 shows stream profile development for the case of a reversal, panels A through $\mathrm{D}$, under the influence of background uplift and a $\mathrm{K}$ value of $1.342 \mathrm{e}-4\left[\mathrm{~L} \cdot \mathrm{T}^{-1}\right]$. In panel $\mathrm{E}$ the initial effect of the 164 meter wide uplift pulse is seen by increase the elevation of the lower part of the profile. After 196,980 model years (panel F) at roughly 500 meters from the river's mouth the model indicates reversal conditions.

Figure 8 shows stream profile development for the case of non-reversal, panels A and B, under the influence of background uplift and a $\mathrm{K}$ value $3.987 \mathrm{e}-4\left[\mathrm{~L}^{-\mathrm{T}^{-1}}\right]$. Panel $\mathrm{C}$ shows the profile take on a more convex form as the 450 meter wide uplift pulse starts to interact with the river. Panel D the river profile is raised to an increased elevation as the pulse moves upstream. Panels $\mathrm{E}$ and $\mathrm{F}$ show the river returning to its previous lower elevation as the pulse continues to move through and beyond the rivers extent. The river returns to its original steady state at 276212 years. 


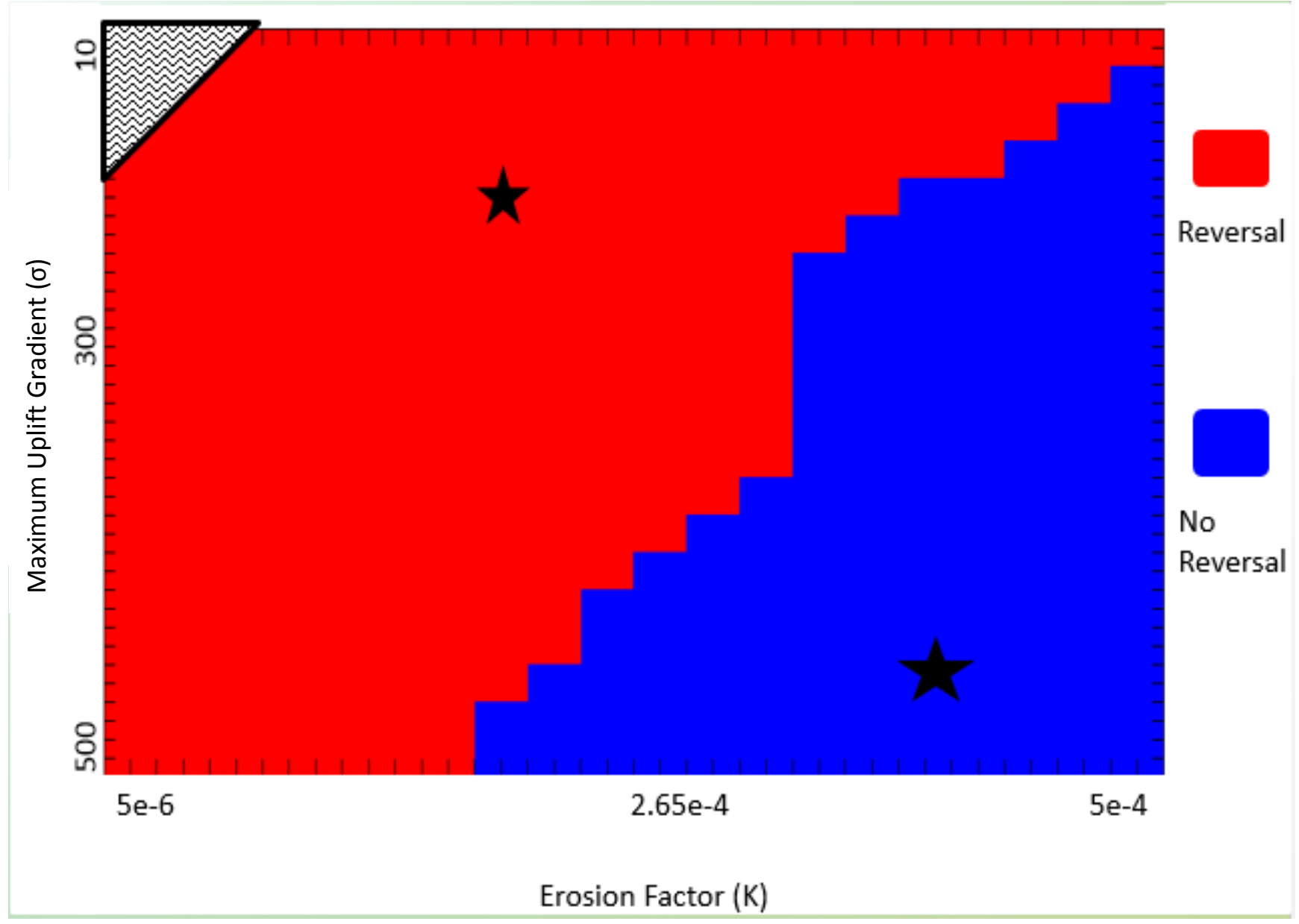

Figure 6: Phase space showing reversal (red) and non-reversal (blue) conditions in terms of erosion factor $(K)$ and uplift gradient $(\sigma)$. Wave pattern indicates unreasonably steep profiles. Stars indicate locations examined in detail. 

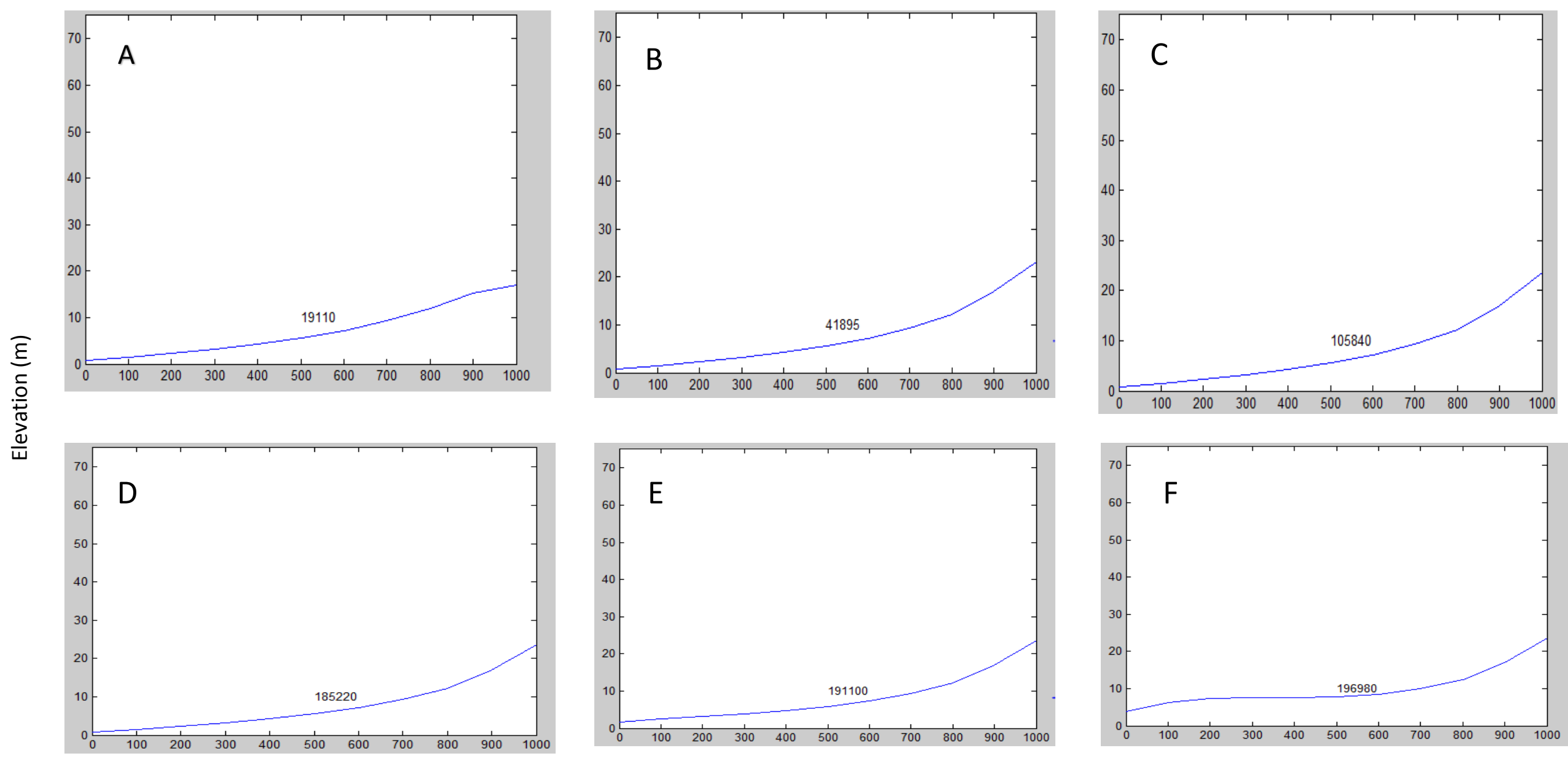

Distance from mouth $(\mathrm{m})$

Figure 7: Diversion. Panels A through F show a rivers longitudinal profile through time as a pulse of uplift migrates across the system; time in years is displayed in the middle of each panel. 

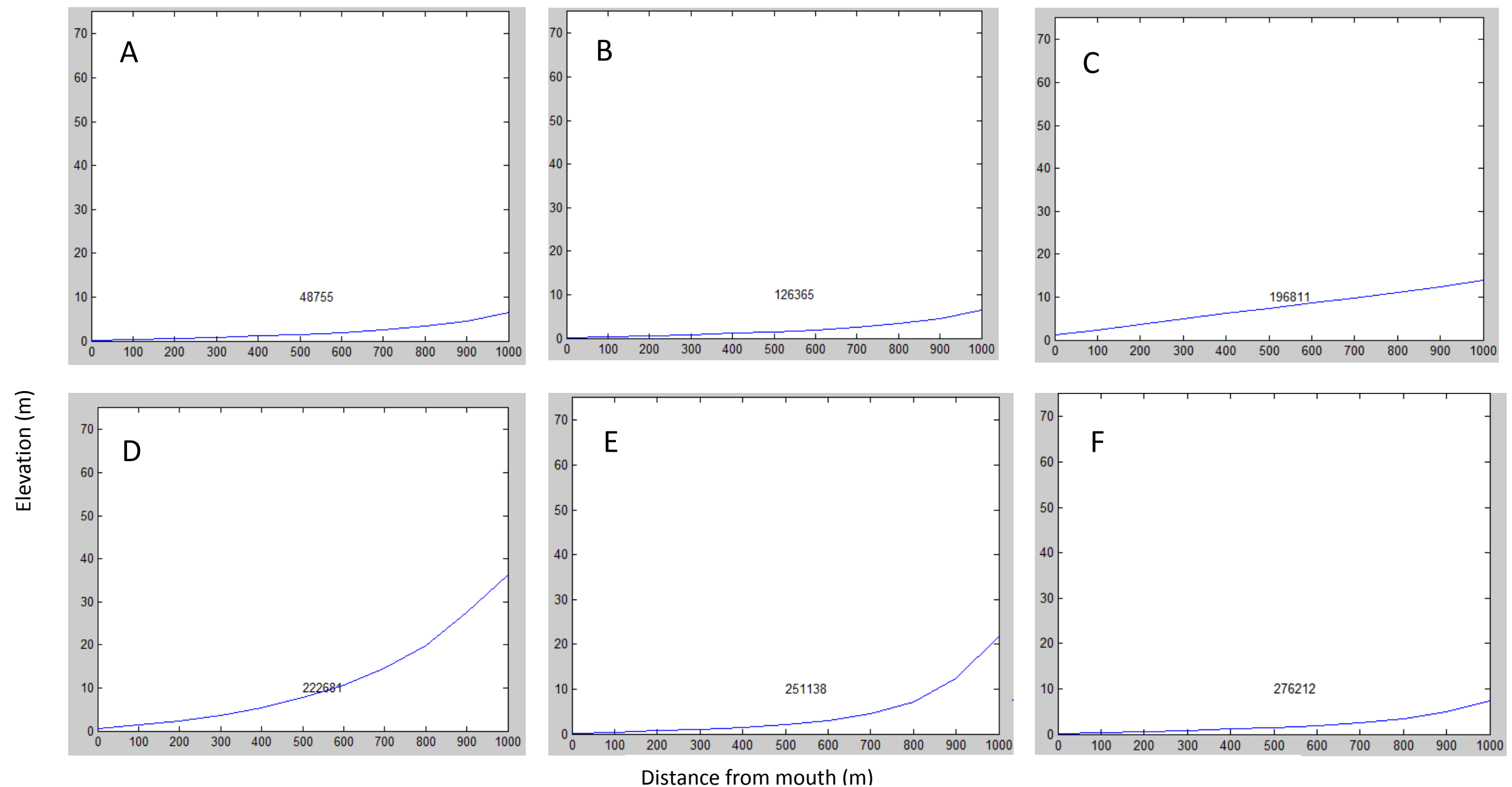

Figure 8: Non diversion. Panels A through F show a rivers longitudinal profile through time as a pulse of uplift migrates across the system; time in years is displayed in the middle of each panel. 


\section{Discussion}

It's easy to assume a drainage system is in a steady state where the controlling elements are in balance. The model in this investigation is setup to explore the transient state of a river's drainage network with observations of the Eel Rivers basin's past reversals and distinctive tectonics as motivation and inspiration. By using a numerical model that combines stream power and uplift (eq. 8.4) I examined the transient conditions of a river in terms of two physical conditions, width of uplift pulse, $\sigma$, and erosion factor, K. By trying multiple combinations of these two parameters, reversals and non-reversal were produced and examined.

My analysis of the phase space, shown in Figure 6, suggests that when all other parameters are fixed, the physical conditions that produce a stream reversal are a narrow uplift pulse and a low erosion factor. When erosion factor is high and/or when the width of the pulse is wider the river does not reverse. A high erosion factor allows the river to incise through at a pace that keeps up with the uplift pulse and a wide uplift pulse presents the river with a less steep leading edge. Certain combinations of conditions, marked by the blue region (fig. 6), that do not reverse, do however experience an increase in elevation as the migrating pulse move across the profile but the downstream slope does not become negative. Starting the center of the pulse of the uplift out in front of the river's mouth allows the elevation profile to develop as a function of background uplift before the pulse propagates through.

Diagram panels A and B, in Figure 7, show uplift and erosion stabilize to a profile that remains unchanged up to panel D. Panel E shows the near profile start to uplift under the influence of the pulse until panel $\mathrm{F}$ where the uplift overwhelms the factor of erosion and a 
reversal happens. While in contrast Figure 8 shows the rivers profile stabilizing in panels $\mathrm{A}$ and $\mathrm{B}$ until panel $\mathrm{C}$ where the leading edge of the uplift pulse is causing the shape of the profile to become more convex. The uplift pulse migrates upstream and the headwaters are raised roughly 30 meters in panel D, about three times the stable elevation. After this point (fig. 8, panel E) the profile takes a highly concave up form, this is a result of the tectonic pulse migrating beyond the head waters, uplift weakening and erosion factor rapidly incising. As the pulse propagates further the profiles elevation decreases until returning to the same elevation as panel A.

These two examples highlight the idea that at transient vs. steady state of landscape is timeframe and space dependent. By their very nature the conditions that cause transient behavior in a landscapes are themselves transient. Bedrock river channels communicate the controlling tectonic and erosion factors of a drainage basin throughout its topography (Whipple and Tucker, 1999). The detachment limited stream power erosions used in this model serves as a great vehicle to view the relationship between the controlling physical factors, shape and patterns of a river through time.

By design the uplift pulse mimics a unique tectonic regime that causes focused and geologically rapid uplift rates causing a drainage network to respond in ways found only in a few place around the world. The model presented here was not meant to replicate the landscape evolution of northern California however the previous research done on the Eel River provided insight into the reasonability of the parameters used and the results. This investigation will serve as basis for future work, further calibrating the model to the Eel River and the Mendocino Crustal Conveyor tectonics.

Expanding on this model would mean removing some of the simplifying elements. For example by letting sediment be deposited or moving to a 2 dimensional environment to allow 
lateral meandering would certainly add complexity. These two alterations could have consequences in terms of the produced results. The two elements would certainly change the how, when and if the river system arrives at an initial steady state. For example sediment deposition could cause the river to dam itself and/or overwhelm erosion which could lead to reversals before the uplift pulse even enters the basin. Added complexity might mean a more realistic model but it does not eliminate the need to justify ones results.

\section{Conclusion}

This study reveals the connection between the river, the tectonics and the topography of its basin. The interplay between these three elements drives the evolution of the landscape. A numerical model forged from the stream power equation and a Gaussian uplift pulse allows us to explore the physical conditions that surround drainage reversals when these two factors are out of balance. The results suggest that when the erosion factor, $\mathrm{k}$, in stream power is low and uplift increase rapidly, a small $\sigma$, are the physical conditions that produce such reversals. By not relying on external elements such as flood events and big landslides the importance of erosion and uplift in these systems as the controlling factors is emphasized. Even the simple one dimensional model that does not allow for deposition presented here can produce drainage reversal conditions. The rivers of northern California, especially the Eel River, will continue to provide motivation and context as this investigation goes on. The work presented here will serve as a foundation to expand on. 


\section{References}

Brocard, G., Willenbring, J., Suski, B., Audra, P., Authemayou, C., Cosenza-Muralles, B., Moran-Ical, S., Demory, F., Rochette, P., Vennemann, T., Holliger, K., and Teyssier, C., 2012, Rate and processes of river network rearrangement during incipient faulting: The case of the Cahabon River, Guatemala: American Journal of Science, v. 312, p. 449-507.

Crosby, B.T., and Whipple, K.X., 2006, Knickpoint initiation and distribution within fluvial networks: 236 waterfalls in the Waipaoa River, North Island, New Zealand: Geomorphology, v. 82, p. 16-38.

Ethridge, F.G., Wohl, E., Gellis, A., Germanoski, D., Hayes, B.R., and Ouchi, S., 2012, Memorial to Stanley A. Schumm: Geological Society of America,.

Howard, A.D., and Kerby, G., 1983, Channel changes in badlands: Geological Society of America Bulletin, v. 94, p. 739-752.

Lock, J., Furlong, K., Woolace, A., and Kelsey, H., 2006, Late Neogene and Quaternary landscape evolution of the northern California Coast Ranges: Evidence for Mendocino triple junction tectonics: Geological Society of America Bulletin, v. 118, p. 1232-1246.

Marshak, S., 2001, Earth: Portrait of a Planet: New York, W. W. Norton \& Company Inc.

Ollier, C., 1981, Tectonics and Landforms (K. M. Clayton, Ed.): New York, Longman Group Limited.

Pelletier, J., 2008, Quantitative Modeling of Earth Surface Processes: New York, Cambridge University Press.

Petts, G.E., and Amoros, C., 1996, Fluvial Hydrosystems: London, Chapman \& Hall.

Ritter, D.F., Kochel, R.C., and Miller, J.R., 2011, Process Geomorphology: Long Grove, Waveland Press Inc.

Schumm, S.A., Dumont, J.F., and Holbrook, J.M., 2002, Active Tectonics and Alluvial Rivers: New York, Cambridge University Press.

Shephard, G.E., Müller, R.D., Liu, L., and Gurnis, M., 2010, Miocene drainage reversal of the Amazon River driven by plate-mantle interaction: Nature Geoscience, v. 3, p. 870-875.

Whipple, K.X., and Tucker, G.E., 1999, Dynamics of the stream-power river incision model: Implications for height limits of mountain ranges, landscape response timescales, and research needs: Journal of Geophysical Research, v. 104, p. 661-674. 
Willenbring, J.K., Gasparini, N.M., Crosby, B.T., and Brocard, G., 2013, What does a mean mean? The temporal evolution of detrital cosmogenic denudation rates in a transient landscape: Geology,, p. 1-4. 


\section{Appendix 1: Literature Review}

Stanley A. Schumm started publishing his research on drainage systems in 1956 and didn't stop for 50 years (Ethridge et al., 2012). Schumm is cited or credited in almost every piece of research listed above and below in this proposal. His book, Active Tectonics and Alluvial Rivers, has not just invaluable background on the subject matter but a number case studies in which specific river systems' response to tectonics is discussed (Schumm et al., 2002). He and co-authors produced a comprehensive body of work by incorporating "old school" experimental research and modern quantitative case studies. Emulating this approach is a goal of the research proposed here.

The research done by Lock et al. in their 2006 article, Late Neogene and Quaternary landscape evolution of the northern California Coast Ranges: Evidence for Mendocino triple junction tectonics, not only examines the connection between the tectonics and the landscape evolution in the region near the Mendocino triple junction but also looks at the rates involved with the of the uplift mechanism (Lock et al., 2006). With two large river drainage basins, the Eel and the Russian, and the California Coast Ranges interaction, showing evidence of drainage reorganization, this research and specific study area is of will be key to the research proposed here. Like falling dominoes, this article links the effects of the migrating junction, crustal thickening and rates of uplift to the present in rivers morphology (Lock et al., 2006). In addition, the article by Whipple and Tucker entitled Dynamics of the stream-power river incision model: Implications for height limits of mountain ranges, landscape response timescales, and research needs, continues this quantitative approach. The focus here is physics and equations behind stream driven incision/erosion of a drainage basin (Whipple and Tucker, 1999). In the big picture there are forces altering the ground and disrupting the existing drainage system and there are the 
forces of the drainage system itself counteracting this. By modeling, their interaction hopefully the critical points can be found.

The research done by Howard and Kerby on the stream channels in the Virginia badlands is found in their 1983 paper, Channel changes in badlands. This work sets up the proportional relationship between the shear stress on the bottom of stream channel and the erosion rate, in the context of bedrock incision (Howard and Kerby, 1983). This older study of the physical relationships established here will be key to implementing a model. A focused study on erosion and denudation near Mendocino Triple junction was done by Jane Willenbring of the University of Pennsylvania is present in What does a mean mean? The temporal evolution of detrital cosmogenic denudation rates in a transient landscape. The radioactive isotope of beryllium in sediment provides the authors with a "trail of breadcrumbs" to trace the South Fork of Eel rivers erosion rates as it responded to tectonic disturbances. A resulting computer simulation tested varying patterns of uplift against basin-wide erosion rates (Willenbring et al., 2013). This article is also important because it takes observed lithological/chemical data and extrapolates them to broader erosion rates based on radiometric dating and implements a model based on this.

Tectonics and river systems interact around the globe and so related research has been conducted on areas outside northern California as well. South America's present day Amazon River is a direct product of continental scale plate motion and the orogeny of the Andes Mountain Range (Shephard et al., 2010). The evolution of the river from 40 MYA to present is presented in Miocene drainage reversal of the Amazon River driven by plate-mantle interaction, by Shepard et al.. Although this paper is heavy in geophysics and models using large scale mantle thermodynamics, it demonstrates the larger implications of the work proposed here. The study of the Cahabón River's rearrangement throughout a period of tectonic faulting during the 
Quaternary in Guatemala, is a case where a variety of data collection techniques were used to reconstruct the region's geomorphic past. The paper, Rate and Processes of River Network Rearrangement during Incipient Faulting, uses methods such as electrical resistivity tomography, water isotopic analysis, geomagnetic polarity, litho-chemical analysis and Beryllium dating to tell the story of the Cahabón River's response to faulting (Brocard et al., 2012). Although this beyond the scope of this project the exhaustive methodology illustrates that there is no set way to gather the necessary data. 


\section{Appendix 2: Numerical Model Program Scripts}

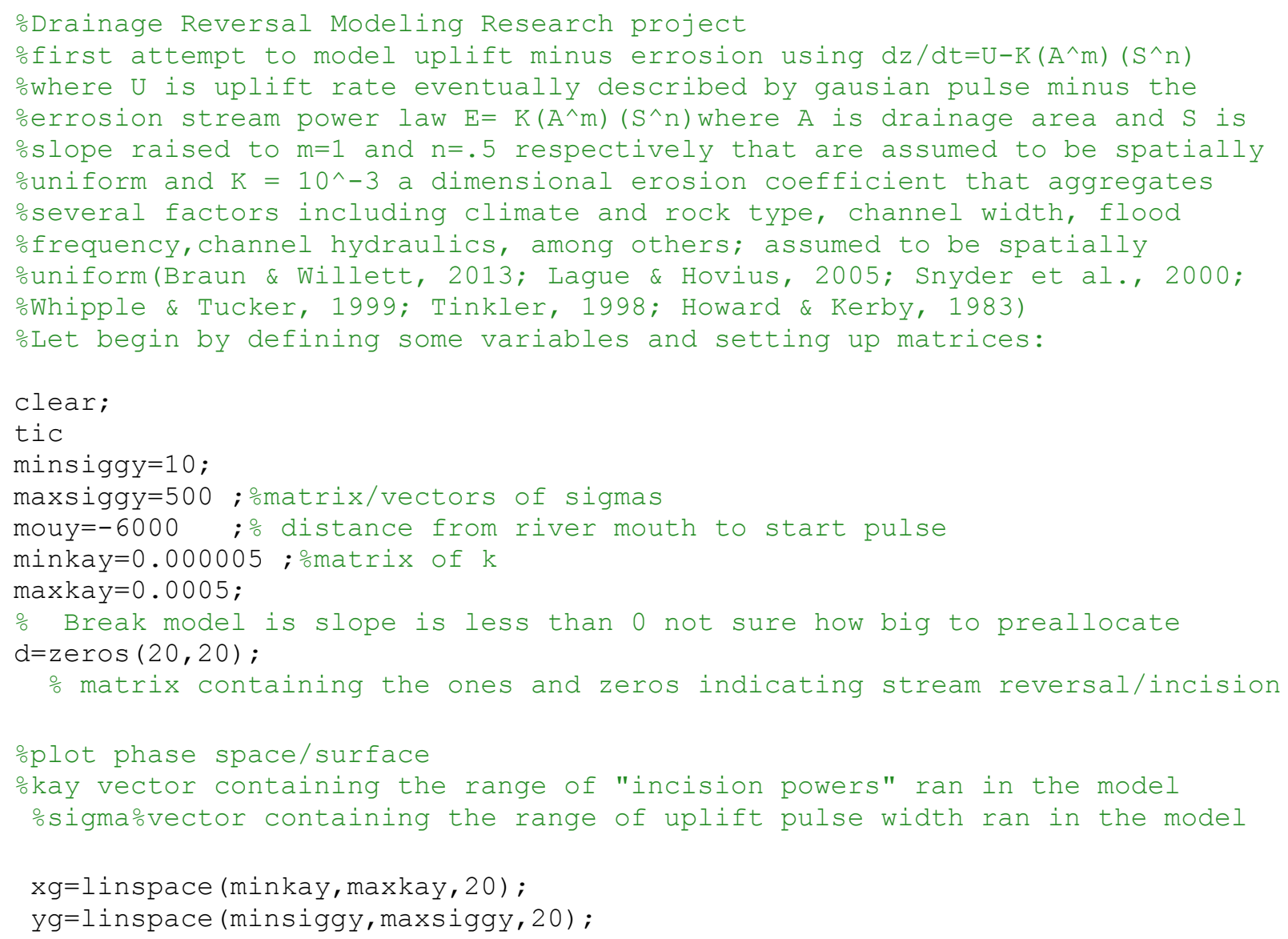




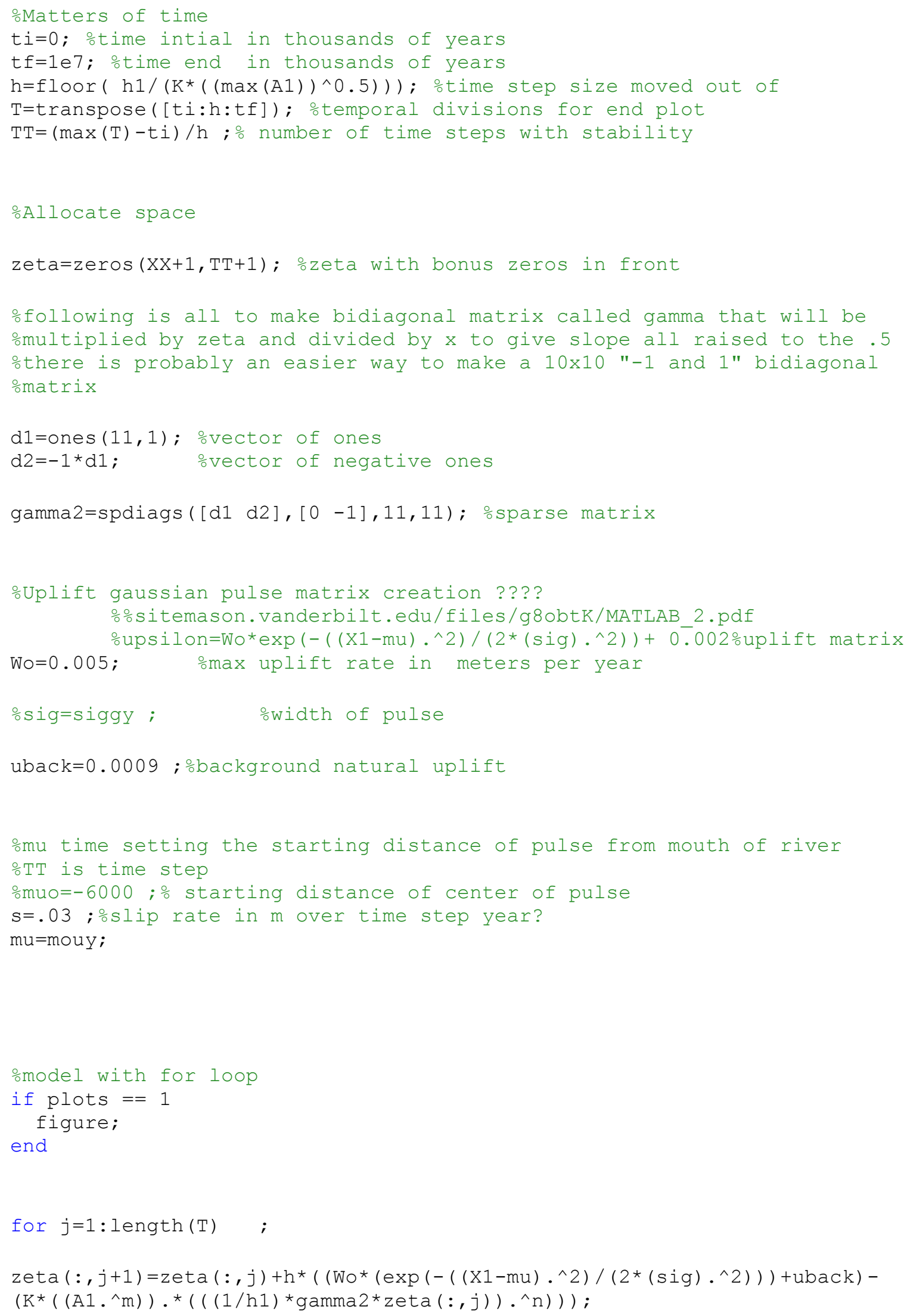




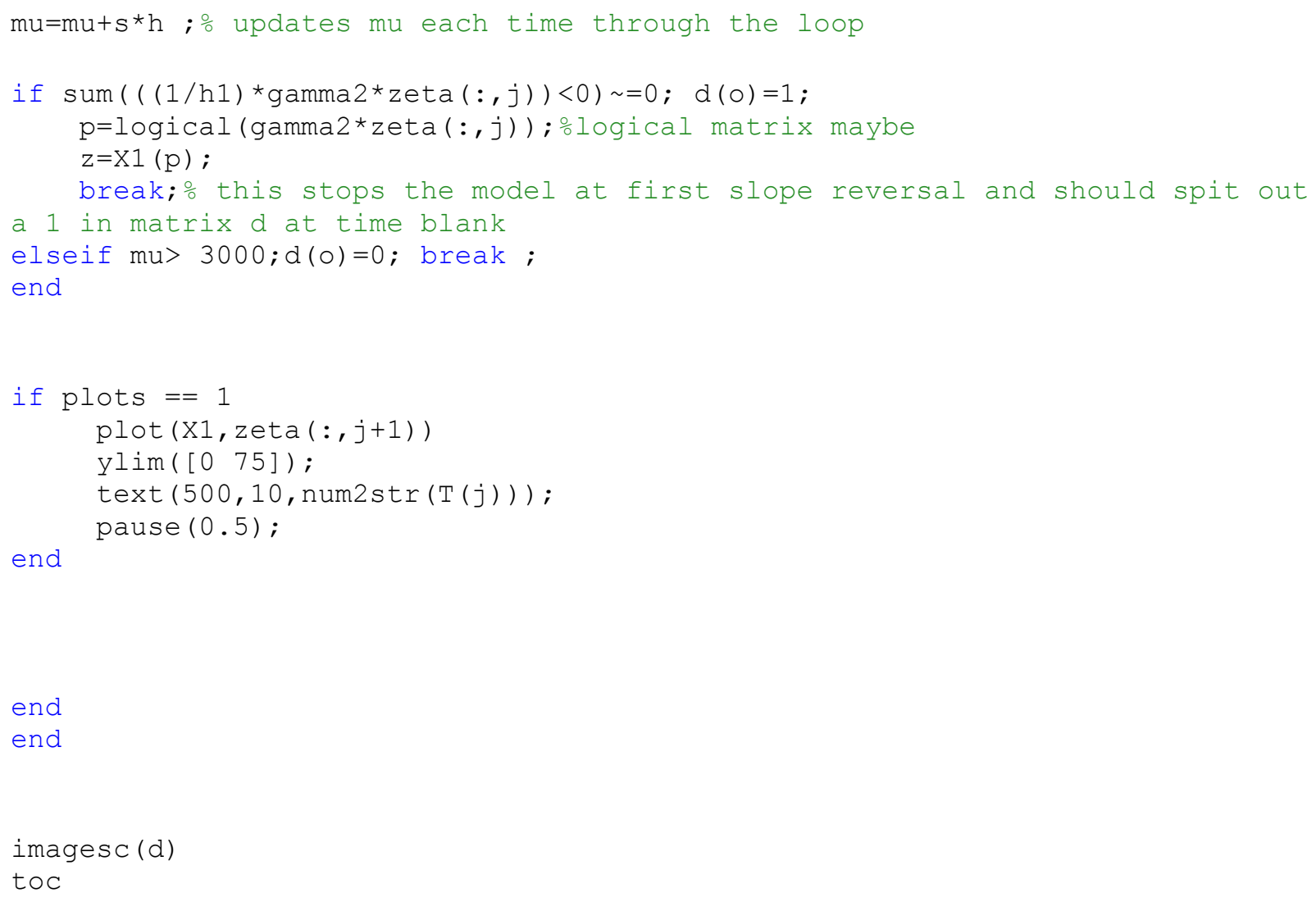

